\title{
PERAWATAN PADA PASIEN ANKYLOGLOSSIA
}

Henry Mandalas ${ }^{\star}$, Widya ${ }^{* *}$

\begin{tabular}{|c|}
\hline Keywords: \\
Frenulum, Lingual \\
frenectomy, \\
Ankyloglossia \\
\hline
\end{tabular}

\section{ABSTRACT}

Background: Ankyloglossia (tongue tie) is a congenital aberration characterized by a thick, toned, or short frenulum that causes limited tongue movement. Lingual frenectomy is performed for the treatment of patients with ankyloglossia. After surgery the patient can lift the tongue to the palate and can reach the labial portion of the maxillary left and right teeth. The purpose of this case report is to report frenectomy treatment in the lingual frenulum.

Case Management: The 14-year-old female patient felt the tongue could not be lifted to the palate and it was difficult to clean the labial portion of the maxillary left and right teeth. On clinical examination the patient's lingualis frenulum is short. The patient get prophylaxis treatment followed by a lingualis frenectomy surgery.

Result: After 1 month control, the patient can lift the tongue to the palate and can clean the labial portion of the maxillary right and left teeth

\section{PENDAHULUAN}

Lidah adalah salah satu organ di rongga mulut yang paling peka pada perubahan yang terjadi di dalam tubuh. Lidah memiliki beberapa fungsi penting yaitu membantu dalam proses pengecapan, mengatur arah makanan ketika dikunyah, membantu proses penelanan, mendorong makanan ke dalam faring (ketika menelan), membersihkan mulut, dan membantu proses berbicara. ${ }^{1}$

Frenulum lingualis adalah lipatan membran mukosa yang menghubungkan lidah ke dasar rongga mulut dan tulang mandibula. Frenulum lingualis terbentuk dari jaringan ikat fibrosa yang padat dan serat superior dari otot genioglossus. Frenulum lingualis bermigrasi menuju posisi sentral untuk menempati posisi definitif seiring dengan pertumbuhan dan perkembangan tulang dan erupsi gigi. Ketika frenulum lingualis tebal, kencang dan atau perlekatan dari lidah terbatas dapat mengakibatkan ankyloglossia. ${ }^{2,3}$

Ankyloglossia biasanya disebut juga dengan tongue-tie, merupakan kelainan kongenital dengan tanda klinis frenulum lingualis rendah yang dapat mempengaruhi terbatasnya pergerakan lidah, kesulitan bicara dan menelan, menyusui serta sulit untuk menjaga kebersihan rongga mulut dan masalah lingkungan sosial. .,4,5 $^{3}$

Fungsi orofasial dapat diubah sesuai dengan tingkat perubahan dari frenulum lingual. Evaluasi frenulum lingual diperlukan, pembedahan diindikasikan bila terdapat keterbatasan pada pergerakan lidah. Frenektomi adalah prosedur yang biasa dilakukan untuk membebaskan frenulum lingual agar lidah dapat bergerak bebas. ${ }^{1,2}$

Pada kasus ini, pasien perempuan berusia 14 tahun merasa lidahnya tidak dapat menyentuh palatum dan sulit untuk

*Departemen Periodonsia Fakultas Kedokteran Gigi Universitas Kristen Maranatha, ${ }^{* *}$ Program Pendidikan Profesi Dokter Gigi Fakultas Kedokteran Gigi Universitas Kristen Maranatha

Korespondensi: h_mandalas@yahoo.com 
menjangkau gigi bagian labial kiri dan kanan rahang atas dengan lidah. Pasien ingin dilakukan perawatan pada lidahnya. Pada pemeriksaan jaringan sekitar lidah, pasien memiliki frenulum lingual yang pendek. Pasien dilakukan bedah frenektomi, setelah kontrol 1 bulan, penyembuhan jaringan baik, lidah pasien dapat menyentuh palatum dan menjangkau gigi bagian labial kiri dan kanan rahang atas dengan lidah.

\section{KASUS}

Pasien perempuan berusia 14 tahun merasa lidahnya tidak dapat menyentuh palatum dan sulit untuk menjangkau gigi bagian labial kiri dan kanan rahang atas. Pasien merasa tidak nyaman dengan keadaan tersebut dan ingin dilakukan perawatan pada lidahnya.

Pada pemeriksaan klinis terlihat frenulum lingualis rendah dan terdapat plak pada regio labial lateral kiri dan kanan rahang atas. Perawatan awal yang dilakukanadalah instruksi kebersihan rongga mulut dan profilaksis seluruh regio rahang atas dan rahang bawah dan dilanjutkan dengan frenektomi lingual agar lidah dapat berfungsi dengan baik.

Persiapan alat, bahan, pasien, operator dan asisten operator, serta pengisian inform consent mengenai tindakan yang akan dilakukan dipersiapkan sebelum tindakan bedah dimulai.

Prosedur awal yang dilakukan pada tindakan bedah adalah tindakan aseptik dengan pengolesan betadine solution 10\% pada ekstraoral dan intraoral dan pemasangan duk bolong, dilanjutkan dengan menganestesi lokal daerah yang akan dilakukan tindakan yaitu bagian ujung lidah, ventral lidah ke arah frenulum, bagian lingual gigi 31 dan 41 dan dasar mulut dengan pehacaine $2 \%$. Stabilisasi lidah menggunakan kasa dan menjepit frenulum lingual menggunakan hemostat, kemudian dilanjutkan dengan pemotongan frenulum menggunakan scalpel dan blade no.15, pemotongan frenulum dilakukan pertama kali pada bagian atas hemostat kemudian dilanjutkan pada bagian bawah hemostat, proses ini dilakukan secara bersamaan dikarenakan pembukaan mulut pasien yang kecil yaitu $25 \mathrm{~mm}$ dan menggunting jaringan untuk pemisahan ujung bagian atas dan bawah menggunakan gunting jaringan. Setelah dilakukan pemotongan frenulum dilakukan penjahitan menggunakan nylon 4.0 dengan jumlah 8 jahitan. Setelah penjahitan selesai daerah operasi kemudian dibersihkan dengan $\mathrm{NaCl}$ fisiologis sebanyak

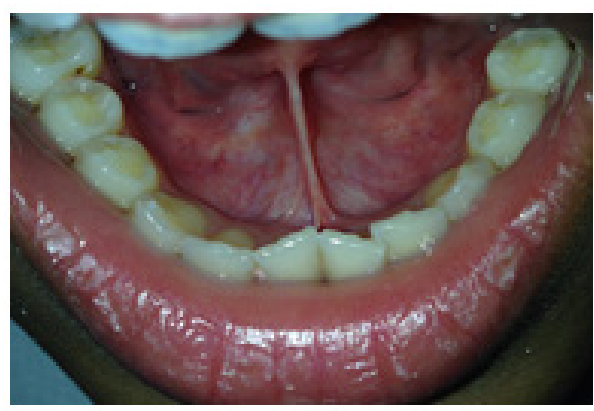

A

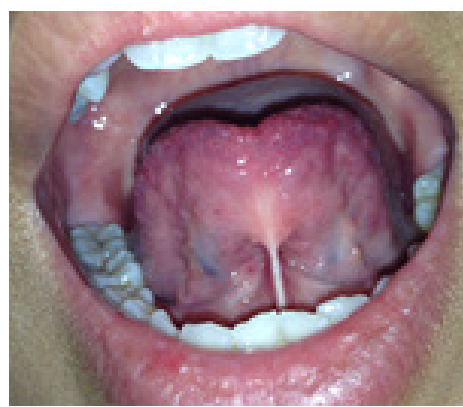

B

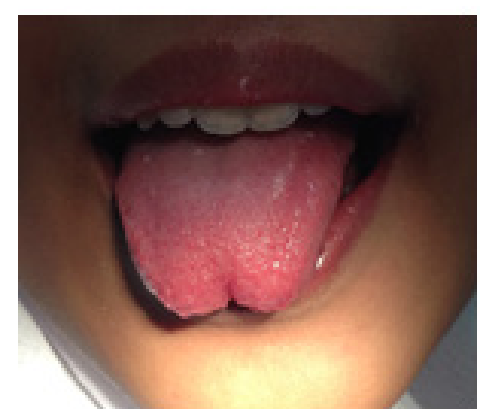

C

Gambar 1. Lidah pasien: A. lidah mengangkat tampak lingual. B. lidah mengangkat ke palatum. C. lidah menjulur tampak depan. 
10cc.

Pasien diberikan medikasi yaitu Amoxicillin tab 500mg no.XII 3dd1, Asam mefenamat tab 500mg no. $X$ 3dd1 dan Minosep garg fls no.l 2dd1 coll oris. Instruksi paska bedah pada pasien adalah dianjurkan tidak makan dan minum 1 jam setelah operasi, hindari makanan yang panas, dingin, asam, pedas dan keras, dianjurkan untuk diet lunak selama beberapa hari, jangan berkumur terlalu keras, jangan meludah, jangan menyentuh luka, dan jangan memainkan lidah, tetap harus menjaga kebersihan mulut di rumah, obat diminum sesuai aturan yang diberikan, jika terjadi perdarahan dan terdapat keluhan segera menghubungi dokter atau Rumah Sakit terdekat,serta pasien disarankan untuk kontrol 1 minggu setelah operasi untuk buka jahitan dan kontrol 1 bulan untuk melihat proses penyembuhan setelah dilakukan tindakan pembedahan.

Sehari setelah dilakukan tindakan pembedahan pasien mengeluhkan adanya pembengkakan pada bagain bawah rahang (submandibula) dan sembuh setelah dua hari. Pada kontrol 1 minggu pasien menyatakan sudah tidak terdapat keluhan dan hasil pemeriksaan klinis terdapat warna kemerahan pada daerah pembedahan. Pada saat kontrol 1 minggu dilakukan pembukaan jahitan pada pasien. Pada saat kontrol 1 bulan setelah dilakukan frenektomi lingual tidak terdapat keluhan serta tidak ada warna kemerahan pada daerah pembedahan. Pasien sudah dapat menggerakan lidah ke palatum serta sudah dapat menggerakan lidah ke bagian labial kiri dan kanan. Operator menginstruksikan pasien melakukan beberapa latihan seperti menjulurkan lidah ke arah hidung, kemudian

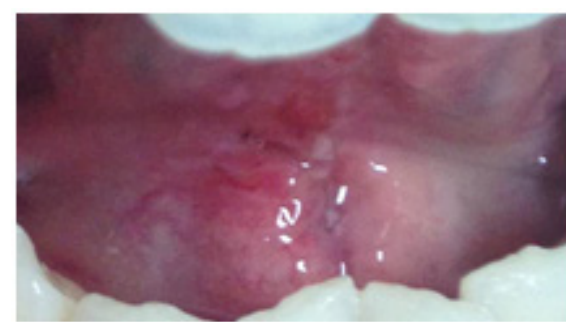

A

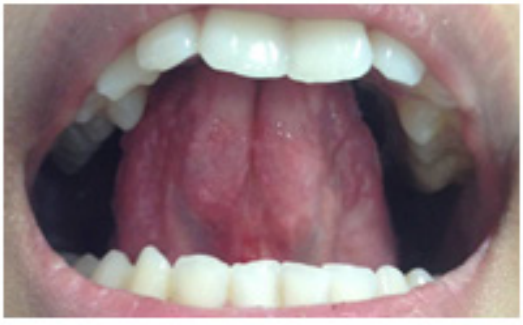

B

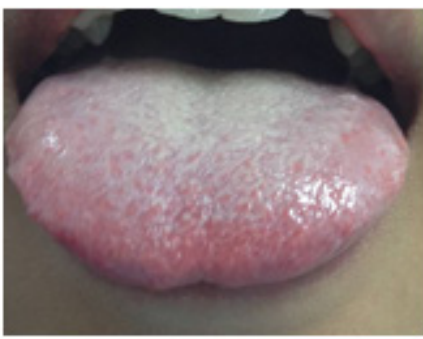

C

Gambar 2. Kontrol 1 minggu : A. lidah mengangkat tampak lingual. B. lidah mengangkat ke palatum. C. lidah menjulur tampak depan

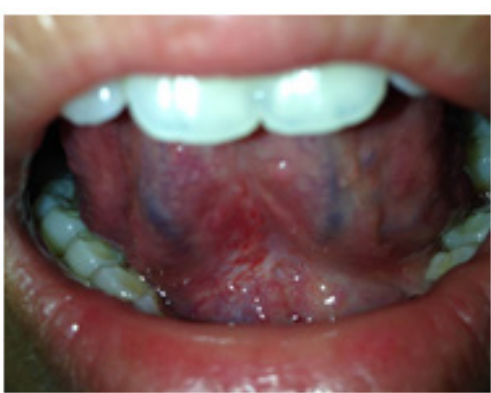

A

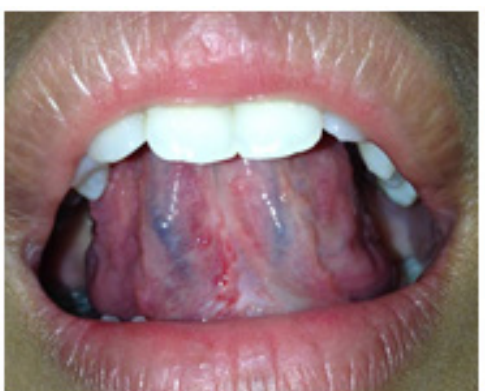

B

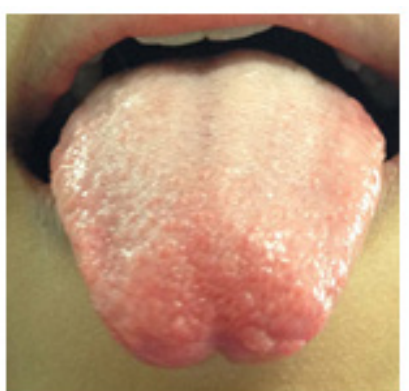

$\mathrm{C}$

Gambar 3. Kontrol 1 bulan A. lidah mengangkat tampak lingual. B. lidah mengangkat ke palatum. C. lidah menjulur tampak depan. 
diturunkan ke arah dagu dan diulangi, membuka mulut dengan lebar dan menyentuh gigi depan dengan lidah saat membuka mulut dan menutup mulut dan menyentuhkan lidah pada pipi bagian dalam kanan dan kiri: selama 3-5 menit, 1-2 kali sehari selama 3-4 minggu paska operasi.

\section{DISKUSI}

Lidah adalah suatu organ yang ditutupi oleh lapisan pelindung dari epitel skuamosa berlapis. Lidah memiliki peran yang penting dalam proses penelanan, pengecapan dan bicara. Banyak kondisi yang dijumpai pada lidah termasuk kedalam istilah "anomali lidah". Salah satu anomali lidah adalah ankyloglossia. Ankyloglossia berasal dari bahasa Yunani yaitu angkylos "tidak lurus", glossia "lidah". Partial ankyloglossia biasanya juga disebut dengan tongue tie dimana kondisi ini disebabkan frenulum yang pendek pada lidah atau frenulum melekat sampai keujung lidah. Ankyloglossia terjadi karena kegagalan dalam degenerasi sel yang mengarah pada hubungan antara lidah dengan dasar mulut. Insidensi dari tongue tie bervariasi dari 0,25\%. Ankyloglossia dapat mempengaruhi cara bicara (terutama sulit untuk mengucapkan huruf $\mathrm{t}, \mathrm{d}, \mathrm{I}$, th, dan s), mastikasi, menyusui untuk bayi, kebersihan mulut dan lingkungan sosial. Ankyloglossia yang sudah parah sering menyebabkan diastema midline mandibular, kerusakan periodontal seperti resesi gingiva disekitar gigi insisivus sentral rahang bawah atau diastema karena adanya tegangan akibat tarikan jaringan dibelakang insisivus mandibula, fungsi lidah yang abnormal pada saat menelan, kesulitan saat makan atau minum, kesulitan dalam memainkan instrumen tiup, kesulitan dalam menjilat makanan seperti es krim, kesulitan menjulurkan lidah sehingga tidak dapat membersihkan makanan yang berada di palatal atau di sulkus labiobukal, dapat mempengaruhi stabilisasi dan adaptasi dari gigi tiruan. $3,4,5,6$

Ankyloglosia menurut Kotklow dapat diklasifikasikan kedalam empat kelas berdasarkan jarak insersi frenum lingual ke ujung lidah. Jarak normal lidah bebas sekitar $16 \mathrm{~mm}$, kelas I: Ankyloglossia ringan: 12 sampai $16 \mathrm{~mm}$, kelas II: Ankyloglossia sedang: 8 sampai $11 \mathrm{~mm}$, kelas III: Ankilogosia parah: 3 sampai $7 \mathrm{~mm}$, kelas IV: Ankilogosia lengkap: kurang dari $3 \mathrm{~mm} .{ }^{5}$

Gambaran klinis ankyloglossia dapat terlihat pada beberapa sindrom seperti Smith Lemliopitz syndrome, Orofacial digital syndrome, Beckwith Weidman syndrome, Simpson Golabi Behmel syndrome dan X-linked cleft palate. ${ }^{7}$

Pembedahan dapat dilakukan sebagai terapi tongue tie adalah frenektomi. Frenektomi merupakan salah satu prosedur bedah preprostetik. Prosedur sederhana dimana sebagian atau seluruh frenulum yang bermasalah dibuang secara bedah dengan tujuan untuk mengembalikan keseimbangan kesehatan mulut dan retensi serta stabilitas gigi tiruan. ${ }^{2,8,9}$

Tujuan Frenektomi adalah untuk kepentingan estetik, membantu memelihara dan memperbaiki oral hygiene, menurunkan resiko kerusakan jaringan periodontal, menghindari relaps (diastema sentral) paska perawatan orto. Indikasi dilakukannya frenektomi adalah perlekatan frenulum yang tinggi, yang memperparah inflamasi gingiva dan poket, diastema sentral, resesi gingiva dan gangguan pada pemeliharaan oral hygiene, mengganggu adaptasi dan stabilisasi dari gigi tiruan. Kontraindikasi untuk dilakukan 
frenektomi adalah pasien dengan riwayat penyakit sistemik seperti diabetes melitus dan hemofilia serta farkto psikologis pasien yang tidak baik. 8,9

Komplikasi yang dapat terjadi pada saat pembedahan adalah kerusakan pada struktur lidah. Selain itu, suturing pada permukaan ventral lidah dapat menyebabkan terhambatnya wharton's duct dan menyebabkan pembengkakan daerah submandibula. Manipulasi pembedahan pada bagian ventral lidah dapat juga melukai nervus lingualis dan dapat menyebabkan mati rasa pada ujung lidah. Suturing dapat juga menghasilkan kontaminasi dari daerah luka karena efek jahitan yang menyebabkan infeksi sekunder yang dapat di hindari dengan antibiotik profilaksis. ${ }^{8}$

Frenektomi frenulum lingualis pada anakanak dianjurkan sedini mungkin karena akan membantu proses bicara, perkembangan rahang dan menghilangkan gangguan fungsi yang mungkin terjadi. Neonatal frenetomy merupakan perawatan ankyloglossia bukan hal baru. Pada abad 18, beberapa reference oleh Marmett ${ }^{10}$ merekomendasi memotong frenulum pada tongue tie bayi untuk membantu bayi dapat menyusui. Ketika diindikasikan frenotomi neonatal merupakan prosedur sederhana dan dapat dilakukan pada klinik gigi. Bayi diijinkan untuk menyusui setelah prosedur dan jarang terjadi komplikasi. Sedangkan pada orang dewasa jika tidak dilakukan dapat mengakibatkan oral hygiene yang buruk. ${ }^{6}$

\section{KESIMPULAN}

Ankyloglossia merupakan suatu kelainan kongenital ditandai dengan frenulum lingualis rendah yang terjadi karena kegagalan dalam degenerasi sel yang mengarah pada hubungan antara lidah dengan dasar mulut. Ankyloglossia harus didiagnosa sedini mungkin untuk menghindari masalah fungsi. Perawatan untuk pasien yang mengalami ankyloglossia adalah frenektomi.

\section{DAFTAR PUSTAKA}

1. Susan, S.,Gray's Anatomy, 39 ed, Oxford: Elsevier., 2008.

2. Olivi G, Signore A, Olivi M. Lingual frenectomy functional evaluation and new therapeutical approach. European journal of pediatric dentistry. 2012.

3. Melo et al, Ankyloglossia: case report.RSBO. 2010.

4. Messner A H, Lalkea L M, Aby J, et al. Ankyloglossia : incidence and associated feeding difficulties. Arch otolaryngol head neck surgery. 2000

5. Kishore, A. Srivastava, V. Ankyloglossia or tongue tie-a case report. Journal of Dental and Medical Sciences (IOSR-JDMS). 2014.

6. Ballard JL, Auer CE, Khoury JC. Ankyloglossia: Assessment, incidence, and effect of frenuloplasty on the breast-feeding dyad. Pediatrics 2002;110:e63.

7. Verdine. V, Khan R, Management of Ankyloglossiacase report. IOSR Journal of Dental and Medical Sciences (IOSR-JDMS). 2013

8. Peterson LJ, Ellis E, Hupp JR, Tucker MR, Contemporary oral and maxillofacial surgery, Elsevier, India, 2003; 527-59

9. Fragiskos D. Oral surgery. Springer. 2007

10. Marmet C, Shell E, Marmet R. Neonatal frenotomy may be necessary to correct breastfeeding problems. J Hum Lactation.1990; 6:117-121. http:// dx.doi.org/10.1177/089033449000600318 